\title{
KARYA SASTRA \\ (PUISI, PROSA, DRAMA)
}

\section{Felta Lafamane}

\begin{abstract}
Abstrak
Karya sastra adalah ungkapan perasaan manusia yang bersifat pribadi yang berupa pengalaman, pemikiran, perasaan, ide, semangat, keyakinan dalam bentuk gambaran kehidupan yang dapat membangkitkn pesona dengan alat bahasa dan dilukiskan dalam bentuk tulisan. Sumardjo dalam bukunya mengatakan bahwa karya sastra adalah sebuh usaha merekam isi jiwa sastrawanya, rekaman ini menggunakan alat bahasa. Sasrta adalah bentuk rekaman dengan bahasa yang akan disampaikan kepada orang lain.sastra adalah seni bahasa. Yang memiliki makna, lahirnya sebuah karya sastra adalah untuk dinikmati diri sendiri atau juda utuk dapat dinikmati oleh siapa saja yang membacanya atau pembacanya. Untuk dapat meulis dan menikmati karya sastra secara sungguh-sugguh dan karya yang baik sangat diperlukan pengetahuan tentang sastra. Tanpa pengetahuan tentang sastra yang cukup, penikmatan akan sebuah karya sastra hanya bersipat dangkal, sementara dan sepintas saja karena kurangnya pemahaman yang tepat. Sangat diperlukan pengatahun akan sastra karena agar semua orang tahu apa yang dimaksud deng sastra. Karya sastra bukanlah ilmu, karya sastra adalah seni yang memiliki unsur kemanusiaan di dalamnya, khususnya perasaan sehingga sangat susah diterapkan untuk metode keilmuan.
\end{abstract}

Keyword: karya sastra, puisi, prosa, drama

\section{Abstract}

Literary works are expressions of human feelings that are personal in the form of experiences, thoughts, feelings, ideas, enthusiasm, belief in the form of a life picture that can arouse charm with language tools and are depicted in written form. Sumardjo in his book said that literature is an attempt to record the contents of the literary soul, this recording uses language tools. Sasrta is a form of recording with language that will be conveyed to others. Literature is the art of language. Which has meaning, the birth of a literary work is to be enjoyed by oneself or also to be enjoyed by anyone who reads it or the reader. To be able to write and enjoy literary works seriously and good works is very necessary knowledge of literature. Without sufficient literary knowledge, the enjoyment of a literary work is only shallow, temporary and cursory due to the lack of proper understanding. It is necessary to know literature for literature so that everyone knows what is meant by literature. Literary work is not a science, literary work is an art that has an element of humanity in it, especially feelings so that it is very difficult to apply to scientific methods.

Keyword: literary works, poetry, prose, drama 
Jenis karya sastra ada tiga, yakni puisi, prosa, dan drama.

Berikut penjelasan tiap karya sastra

\section{Puisi}

\section{a. Pengertian Puisi}

Puisi merupakan bentuk karya sastra dari hasil ungkapan dan perasaan penyair dengan bahasa yang terikat irama, matra, rima, penyusunan lirik dan bait, serta penuh makna. Puisi mengungkapkan pikiran dan perasaan penyair secara imajinatif dan disusun dalam mengonsentrasikan kekuatan bahasa dengan struktur fisik dan struktur batinnya. Puisi mengutamakan bunyi, bentuk dan juga makna yang disampaikan yang mana makna sebagai bukti puisi baik jika terdapat makna yang mendalam dengan memadatkan segala unsur bahasa.

Beberapa pengertian puisi menurut para ahli

1. Herman Waluyo : Pengertian puisi menurut herman waluyo ialah karya sastra tertulis yang paling awal ditulis oleh manusia.

2. Sumardi : Pengertian puisi menurut sumardi ialah karya sastra dengan bahasa yang dipadatkan, dipersingkat, dan diberi irama dengan bunyi yang padu dan pemilihan kata-kata kias (imajinatif).

3. Thomas Carlye : Pengertian puisi menurut thomas carley ialah ungkapan pikiran yang bersifat musikal.

4. James Reevas : Pengertian puisi menurut James Reevas bahwa arti puisi ialah ekspresi bahasa yang kaya dan penuh daya pikat.

5. Pradopo : Pengertian puisi ialah rekaman dan interpretasi pengalaman manusia yang penting, diubah dalam wujud yang paling berkesan.

6. Herbert Spencer : Pengertian puisi ialah bentuk pengucapan gagasan yang bersifat emosional dengan mempertimbangkan keindahan.

b. Ciri - Ciri Puisi

Puisi ialah seni tertulis menggunakan bahasa sebagai kualitas estetiknya (keindahan). Puisi dibedakan menjadi 2 yaitu puisi lama dan juga puisi baru.

1) Puisi Lama

Puisi Lama merupakan puisi yang masih terikat oleh aturan-aturan yaitu sebagai berikut ini :

1. Jumlah kata dalam 1 baris

2. Jumlah baris dalam 1 bait

3. Persajakan (rima)

4. Banyak suku kata di tiap baris

5. Irama 


\section{Ciri-Ciri Puisi Lama}

1. Tak diketahui nama pengarangnya

2. Penyampaiannya yang bersifat dari mulut ke mulut, sehingga merupakan sastra lisan.

3. Sangat terikat akan aturan-aturan misalnya seperti jumlah baris tiap bait, jumlah suku kata ataupun rima.

2) Puisi Baru

Puisi Baru merupakan puisi yang tidak terikat lagi oleh aturan yang mana bentuknya lebih bebas dari pada puisi lama dalam segi jumlah baris, suku kata, ataupun rima.

\section{Ciri-Ciri Puisi Baru}

1. Mempunyai bentuk yang rapi, simetris

2. Persajakan akhir yang teratur

3. Memakai pola sajak pantun dan syair walaupun dengan pola yang lain

4. Umumnya puisi 4 seuntai

5. Disetiap baris atasnya sebuah gatra (kesatuan sintaksis)

6. Ditiap gatranya terdiri dari dua kata (pada umumnya) : 4-5 suku kata

c. Jenis-jenis Puisi

1. Puisi Naratif

Puisi naratif mengungkapkan suatu cerita atau penjelasan penyair. Puisi ini terbagi ke dalam beberapa macam, yakni balada dan romansa. Balada ialah puisi yang berisi cerita tentang orang-orang perkasa ataupun tokoh pujaan. Contoh Balada Orang-orang Tercinta dan Blues untuk Bonnie karya WS Rendra. Romansa ialah jenis puisi cerita yang memakai bahasa romantik yang berisi kisah percintaan, yang diselingi perkelahian dan petualangan.

\section{Puisi Lirik}

Jenis puisi ini terbagi ke dalam beberapa macam, yakni elegi, ode, dan serenade.

1. Elegi ialah puisi yang mengungkapkan perasaan duka. Misal Elegi Jakarta karya Asrul Sani yang mengungkapkan perasaan duka penyair di Kota Jakarta.

2. Serenada merupakan sajak percintaan yang dapat dinyanyikan. Kata "serenada" bermakna nyanyian yang tepat dinyanyikan pada waktu senja. Rendra banyak menciptakan serenada dalam 4 Kumpulan Sajak. Misalnya "Serenada Biru", "Serenada Hitam", "Serenada Merah Jambu", "Serenada Kelabu", "Serenada Ungu", dan lain sebagainya. Warna-warna di belakang serenade itu menggambarkan sifat nyanyian cinta itu, ada yang bahagia, sedih, dan kecewa. 
3. Ode ialah puisi yang berisi pujaan terhadap seseorang, sesuatu hal, atau sesuatu keadaan. Ode banyak ditulis sebagai pemujaan terhadap tokoh-tokoh yang dikagumi contohnya seperti Teratai (karya Sanusi Pane), Diponegoro (karya Chairil Anwar), dan Ode buat Proklamator (karya Leon Agusta).

\section{Puisi Deskriptif}

Dalam jenis puisi ini, penyair bertindak sebagai pemberi kesan terhadap keadaan/peristiwa, benda, atau suasana yang dipandang menarik perhatian. Puisi yang termasuk kedalam jenis puisi deskriptif, misalnya satire dan puisi yang bersifat kritik sosial.

1. Satire ialah puisi yang mengungkapkan perasaan ketidak puasan penyair terhadap suatu keadaan, namun dengan cara menyindir atau menyatakan keadaan sebaliknya.

2. Puisi kritik sosial ialah puisi yang juga menyatakan ketidak puasan penyair terhadap keadaan atau terhadap diri seseorang, namun dengan cara membeberkan kepincangan atau ketidak beresan keadaan atau orang tersebut. Kesan penyairan ini juga dapat kita hayati dalam puisipuisi impresionistik yang mengungkapkan kesan (impresi) penyair terhadap suatu hal.

d. Unsur Dalam Puisi

Ada dua unsur yang membangun suatu puisi, yakni

Unsur intrinsik

Unsur intrinsik puisi merupakan unsur-unsur yang terkandung dalam puisi dan mempengaruhi puisi sebagai karya sastra. Yang termasuk unsur intrinsik puisi ialah diksi, imaji, majas, bunyi, rima, ritme, dan tema.

1. Diksi atau pilihan kata : Dalam membangun puisi, penyair hendaknya memilih kata dengan cermat dengan cara mempertimbangkan makna, komposisi bunyi dalam rima dan irama, kedudukan kata di tengah konteks kata lainnya, dan kedudukan kata dalam suatu puisi keseluruhan.

2. Daya bayang atau imaji : Yang dimaksud dengan daya bayang atau imaji ketika membangun puisi ialah penggunaan kata-kata yang konkret dan khas yang dapat menimbulkan imaji visual, auditif, ataupun taktil.

3. Gaya bahasa atau majas: Gaya bahasa atau majas atau bahasa figuratif dalam puisi ialah bahasa yang dipakai penyair untuk mengatakan sesuatu dengan cara yang tidak biasa atau memakai kata-kata yang bermakna kiasan atau lambing.

4. Bunyi : Bunyi dalam puisi mengacu pada dipakainya kata-kata tertentu sehingga menimbulkan efek nuansa tertentu.

5. Rima : Rima ialah persamaan bunyi atau perulangan bunyi dalam puisi yang bertujuan untuk menimbulkan efek keindahan.

6. Ritme : Ritme dalam puisi adalah dinamika suara dalam puisi agar tidak dirasa monoton bagi penikmat puisi. 
7. Tema : Tema dalam puisi ialah ide atau gagasan pokok yang ingin disampaikan oleh pengarang melalui puisinya.

Unsur ekstrinsik

Unsur ekstrinsik puisi merupakan unsur-unsur yang berada di luar puisi dan mempengaruhi kehadiran puisi sebagai karya seni. Adapun yang termasuk dalam unsur ekstrinsik puisi ialah aspek historis, psikologis, filsafat, dan religious.

1. Aspek historis merupakan unsur-unsur kesejarahan atau gagasan yang terkandung dalam puisi.

2. Aspek psikologis merupakan aspek kejiwaan pengarang yang termuat dalam puisi.

3. Aspek filsafat Beberapa ahli menyatakan bahwa suatu filsafat berkaitan erat dengan puisi atau karya sastra keseluruhan dan beberapa ahli lainnya menyatakan bahwa filsafat dan karya sastra dalam hal ini puisi tidak saling terkait satu sama lain.

4. Aspek religius dalam puisi mengacu pada tema yang umum diangkat dalam puisi oleh pengarang.

e. Struktur Dalam Puisi

Struktur Batin

Struktur batin puisi bisa disebut juga sebagai hakikat suatu puisi, yang terdiri dari beberapa hal, seperti :

1. Tema/ Makna (sense)

Ini ialah unsur utama dalam puisi karena dapat menjelaskan makna yang ingin disampaikan oleh seorang penyair dimana medianya berupa bahasa.

2. Rasa (feeling)

Ini ialah sikap sang penyair terhadap suatu masalah yang diungkapkan dalam puisi. Pada umumnya, ungkapan rasa ini berkaitan dengan latar belakang sang penyair, misalnya agama, pendidikan, kelas sosial, jenis kelamin, pengalaman sosial, dan lain-lain.

3. Nada (tone)

Nada adalah sikap seorang penyair terhadap audiensnya serta sangat berkaitan dengan makna dan rasa. Melalui nada, seorang penyair dapat menyampaikan suatu puisi dengan nada mendikte, menggurui, memandang rendah, dan sikap lainnya terhadap audiens.

4. Tujuan (intention)

Tujuan/ maksud/ amanat ialah suatu pesan yang ingin disampaikan oleh sang penyair kepada audiensnya.

Struktur Fisik 
Struktur fisik suatu puisi bisa disebut juga dengan metode penyampaian hakikat suatu puisi, yang terdiri dari beberapa hal berikut ini :

\section{Perwajahan Puisi (tipografi)}

Tipografi ialah bentuk format suatu puisi, seperti pengaturan baris, tepi kanan-kiri, halaman yang tidak dipenuhi kata-kata. Perwujutan puisi ini sangat berpengaruh pada pemaknaan isi puisi itu sendiri.

\section{Diksi}

Diksi merupakan pemilihan kata yang dilakukan oleh seorang penyair dalam mengungkapkan puisinya sehingga didapatkan efek sesuai dengan yang diinginkan. Pemilihan kata pada puisi sangat berkaitan dengan makna yang ingin disampaikan oleh sipenyair.

\section{Imaji}

Imaji ialah susunan kata dalam puisi yang bisa mengungkapkan pengalaman indrawi sang penyair (pendengaran, penglihatan, dan perasaan) sehingga dapat mempengaruhi audiens seolah-olah merasakan yang dialami sang penyair.

\section{Kata Konkret}

Kata konkret merupakan bentuk kata yang bisa ditangkap oleh indera manusia sehingga menimbulkan imaji. Kata-kata yang dipakai umumnya berbentuk kiasan (imajinatif), misalnya penggunaan kata "salju" untuk menjelaskan kebekuan jiwa.

\section{Gaya Bahasa}

Gaya bahasa merupakan penggunaan bahasa yang bisa menimbulkan efek dan konotasi tertentu dengan bahasa figuratif sehingga mengandung banyak makna. Gaya bahasa ini bisa disebut juga dengan majas (metafora, ironi, repetisi, pleonasme, dan lain-lain).

\section{Rima/ Irama}

Irama/ rima ialah adanya persamaan bunyi dalam penyampaian puisi, baik di awal, tengah, maupun di akhir puisi. Beberapa bentuk rima yakni :

Onomatope, yakni tiruan terhadap suatu bunyi. Misalnya 'ng' yang mengandung efek magis.

Bentuk intern pola bunyi, yakni aliterasi, asonansi, persamaan akhir, persamaan awal, sajak berselang, sajak berparuh, sajak penuh, repetisi, dan sebagainya.

Pengulangan kata, yakni penentuan tinggi-rendah, panjang-pendek, keras-lemah suatu bunyi.

\section{Contoh Puisi}

Hujan Bulan Juni 
Karya Sapardi Djoko Damono

Tak ada yang lebih tabah dari hujan bulan juni

dirahasiakannya rintik rindunya

kepada pohon berbunga itu

tak ada yang lebih bijak

dari hujan bulan juni

dihapuskannya jejak-jejak kakinya

yang ragu-ragu dijalan itu

tak ada yang lebih arif

dari hujan bulan juni

dibiarkannya yang tak terucapkan

diserap akar pohon bunga itu

\section{Prosa}

a. Pengertian Prosa

Prosa adalah sebuah karya sastra yang bentuk tulisannya bebas \& tidak terikat dengan berbagai aturan, seperti rima, diksi, irama, \& lain-lainnya. Secara bahasa ( Etimologis), kata prosa berasal dari Bahasa Latin “Prosa” artinya terus terang. Dan Karya Sastra Prosa juga diartikan karya sastra yang dipakai sebagai mendeskripsikan suatu fakta.

b. Manfaat \& Ciri-Ciri Prosa

Prosa juga bisa dimanfaatkan sebagai Surat kabar, novel, majalah, ensiklopedia, surat kirim, dan beragam jenis media lainnya.

\section{Ciri-Ciri Prosa}

1. Bentuknya Bebas

2. Prosa mempunyai bentuk yang tidak terikat oleh : baris, bait, suku kata, \& irama.

3. Pada umumnya bentuk prosa adalah sebuah rangkaian kalimat yang membentuk suatu paragraf. Contoh : Dongeng, Hikayat, Novel \& lainnya. Dan dapat disajikan sebagai bentuk tulisan ataupun secara lisan.

4. Memiliki Tema 
Sebuah Prosa memiliki sebuah tema yang menjadi dasar dalam sebuah cerita \& merupakan bahasan pokok di dalamnya.

5. Mengalami Perkembangan

Sebuah Prosa akan mengalami suatu perkembangan karena dipengaruhi pada perubahan yang berada di kalangan masyarakat.

6. Mempunyai Urutan Peristiwa

7. Dalam Prosa biasanya terdapat alur cerita yang menjelaskan urutan sebuah peristiwa. Dan alur peristiwa tersebut, berbentuk alur mundur, maju, \& campuran.

8. Mempunyai Tokoh di Dalamnya

Di dalam prosa terdapat tokoh, yaitu itu manusia, hewan, maupun tumbuhan. Dan mempunyai suatu sifat \& sikap yaitu Antagonis (Jahat), Protagonis(Baik), \& Tokoh Pembantu.

9. Memiliki Latar

Sebuah Prosa mempunyai sebuah latar pada masing-masing suatu kejadian, yaitu itu latar tempat, waktu, \& suasana.

10. Memiliki Suatu Amanat

Sebuah Prosa harus memiliki sebuah amanat yang akan disampaikan kepada pembaca atau pendengarnya, sehingga dapat mempengaruhi mereka.

11. Memakai Bahasa Asing Sebuah Prosa dapat menggunakan bahasa asing, contoh Bahasa Inggris, Bahasa Jepang, Bahasa Melayu, dan Bahasa Asing lainnya atau juga tidak menggunakan Bahasa Asing.

12. Memiliki Nama Pengarang

Sebuah Prosa pasti ada nama pengarangnya. Tetapi, nama pengarang tidak harus dipublikasikan.

c. Jenis-Jenis Prosa

Prosa dibagi menjadi 2 Bagian, yaitu Prosa Lama \& Prosa Baru.

1) Prosa baru

Prosa Baru adalah Prosa yang dikarang bebas tanpa aturan apapun setelah menerima Literatur atau pengaruh Budaya Barat.

Jenis-jenis Prosa Baru

a) Roman

Roman adalah sebuah bentuk prosa yang mengkisahkan suatu pelaku utama yang suka dukanya dalam kehidupan. Bentuk Prosa ini mengkisahkan tentang kehidupan pelaku utamanya dari awal kehidupannya hingga saat akhir hidupnya. Roman juga dibagi menjadi beberapa macam, yaitu Roman Trasendensi, Roman Sosial, Roman Sejarah, Roman Psikologis, \& Roman Detektif.

a) Novel

Novel adalah sebuah bentuk prosa yang menggambarkan sebagian kehidupan peran utamanya hanya yang terpenting, paling menarik, \& yang mengandung sebuah konflik. 
c) Cerpen

Cerpen adalah sebuah bentuk prosa yang mengkisahkan sebagian kecil kehidupan tokoh-tokohnya hanya yang terpenting \& paling menarik.

d) Riwayat

Riwayat atau Biografi adalah sebuah bentuk prosa berisikan tentang pengalaman hidup sang pengarang sendiri (autobiografi) atau pengalaman hidup orang lain, dari kecil sampai dewasa atau sampai meninggal dunia.

e) Kritik

Kritik adalah sebuah bentuk prosa untuk menguraikan suatu pendapat bagus atau buruknya pada suatu karya, dan memberikan suatu alasan tentang isi \& bentuk dengan kriteria yang bersifat objektif \& menghakimi.

f) Resensi

Resensi adalah sebuah bentuk prosa tentang pembicaraan, pertimbangan atau ulasan pada suatu karya sastra.

g) Esai

Esai adalah sebuah bentuk prosa yang sebagai suatu ulasan atau kupasan pada masalah secara sepintas berdasarkan pandangan pribadi pengarang.

2) Prosa Lama

Prosa Lama adalah Prosa yang masih murni menggunakan Bahasa Indonesia yang belum dipengaruhi Budaya Barat. Karya Sastra prosa lama ini awal mulanya hanya disampaikan secara lisan, karena pada saat itu masyarakat belum mengetahui tulisan. Tetapi setelah Agama \& Kebudayaan Islam telah masuk di Indonesia, saat itulah masyarakat mulai mengenal tulisan. Berikut ini adalah bentuk-bentuk prosa lama :

a) Hikayat

Hikayat adalah Suatu prosa yang menceritakan suatu kejadian yang tidak masuk akal \& menggambarkan tentang kehidupan Para Raja, Ratu, Pangeran, Putri, Para Dewa \& Dewi yang mempunyai sebuah kekuatan gaib yang luar biasa.

b) Sejarah

Sejarah (Tambo) adalah suatu prosa yang menceritakan tentang suatu peristiwa atau kejadian yang nyata dan telah terjadi pada zaman dahulu. Selain menceritakan suatu peristiwa sejarah, dan dapat menceritakan silsilah pada seorang Raja. 
c) Kisah

Kisah adalah Sebuah prosa yang menggambarkan suatu Kisah Perjalanan atau Pelayaran Seseorang dari Satu Tempat Ke Tempat Lainnya.

d) Dongeng

Dongeng adalah Sebuah prosa yang menggambarkan suatu cerita fiksi. Dongeng juga mempunyai beberapa ragam dibawah ini :

(1) Fabel

Fabel adalah Sebuah karya sastra yang menggambarkan cerita lama yang dimana Hewan sebagai tokohnya dan ditujukan sebagai lambang pengajaran suatu moral (biasa pula disebut sebagai cerita binatang).

(2) Mitos

Mitos adalah Sebuah karya sastra yang menceritakan tentang kepercayaan terhadap sebuah benda atau hal lainnya yang dipercayai mempunyai kekuatan gaib.

(3) Legenda

Legenda adalah Sebuah karya sastra yang menggambarkan cerita lama tentang riwayat terjadi dan terbentuknya suatu tempat atau wilayah.

(4) Sage

Sage adalah Sebuah karya satra yang menggambarkan cerita lama yang berhubungan dengan sebuah keberanian atau kesaktian \& keajaiban pada seseorang.

(5) Parabel

Parabel adalah Sebuah karya sastra yang menggambarkan cerita rekaan keagamaan atau sikap moral dan melibatkan ibarat atau perbandingan.

(6) Dongeng Jenaka

Dongeng Jenaka adalah Sebuah karya sastra yang menggambarkan tentang tingkah laku seseorang yang malas, rajin, bodoh atau cerdik, dan diceritakan secara humor.

(7) Cerita Berbingkai

Cerita Berbingkai adalah Sebuah karya sastra yang menggambarkan suatu cerita yang didalamnya mempunyai cerita lagi lalu dibicarakan oleh tokoh-tokoh yang ada didalam cerita tersebut.

d. Perbedaan Prosa Lama \& Prosa Baru 
Perbedaan antara Prosa Lama \& Prosa Baru adalah :

1. Prosa lama

1. Statis, lambat perubahannya.

2. Istana Sentris atau bersifat kerajaan.

3. Bersifat fantastis, bentuknya seperti hikayat \& dongeng.

4. Di pengaruhi sastra Hindu \& Arab.

5. Tidak dicantumkan nama pengarang.

2. Prosa baru

1. Dinamis, cepat prubahannya.

2. Rakyat Sentris, mengambil cerita dari rakyat sekitar.

3. Realistis, bentuknya seperti roman, novel, cerpen \& drama, dll.

4. Di pengaruhi sastra Barat yaitu Bahasa Inggris, Jepang, dll.

5. Nama pencipta selalu dicantumkan.

3. Drama

a. Pengertian Drama Adalah

Drama adalah genre karya sastra berupa karangan yang menggambarkan atau mengilustrasikan realita kehidupan, watak, dan tingkah laku manusia dimana kisah di dalamnya disampaikan melalui peran dan dialog.

Pendapat lain mengatakan pengertian drama adalah jenis karya sastra yang menggambarkan suatu kisah, watak, dan tingkah laku manusia melalui peran dan dialog yang ditampilkan di atas panggung dalam beberapa babak. Secara etimologis, kata "drama" diadaptasi dari bahasa Yunani, yaitu "draomai" yang artinya bertindak, berbuat.

Kisah dan cerita dalam drama mengandung konflik dan emosi yang bertujuan untuk mempengaruhi orang yang melihat atau mendengar drama tersebut. Naskah drama diperankan oleh aktor yang memiliki kemampuan untuk menyajikan konflik dan emosi secara utuh.

Pengertian Drama Menurut Para Ahli

Agar lebih memahami apa itu drama, maka kita dapat merujuk pada pendapat beberapa ahli berikut ini:

1. Balthazar Vallhagen

Menurut Balthazar Vallhagen, pengertian drama adalah suatu seni yang menggambarkan alam dan sifat manusia dalam bentuk gerakan.

2. Anne Civardi

Menurut Anne Civardi, drama adalah suatu kisah yang diceritakan melalui gerakan dan kata-kata. 


\section{Ferdinand Brunetierre}

Menurut Ferdinand Brunetierre, pengertian drama adalah suatu karya sastra yang disampaikan dengan aksi atau gerakan dan melahirkan keinginan bagi yang melihatnya.

4. Budianta dkk

Menurut Budianta dkk, pengertian drama adalah jenis karya sastra dimana penampilan fisiknya memperlihatkan secara verbal adanya dialog antar tokoh.

\section{Seni Handayani}

Menurut Seni Handayani, drama adalah bentuk komposisi berdasarkan dua cabang seni, seni sastra dan seni pertunjukan sehingga drama dibagi menjadi dua, yaitu drama dalam bentuk teks tertulis dan drama dipentaskan.

\section{b. Ciri-Ciri Drama}

Drama memiliki karakteristik yang berbeda dengan jenis karya sastra lainnya. Adapun ciri-ciri drama adalah sebagai berikut:

1. Seluruh kisah dalam cerita drama disampaikan dalam bentuk dialog, baik dialog antar tokoh maupun dialog tokoh dengan dirinya sendiri (monolog).

2. Drama harus memiliki tokoh atau karakter yang diperankan oleh manusia, wayang, atau boneka.

3. Dalam drama harus terdapat konflik atau ketegangan yang menjadi inti dari cerita drama.

4. Durasi waktu pementasan drama dapat berlangsung selama sekitar tiga jam.

5. Pementasan drama biasanya dilakukan di atas panggung yang telah dilengkapi beberapa perlengkapan dan peralatan untuk menghidupkan suasana.

6. Pertunjukan drama selalu dilakukan dihadapan penonton dimana drama tersebut dilakukan sebagai sarana hiburan

\section{c. Struktur Dalam Drama}

Dalam drama terdapat struktur alur yang tertata dan mengandung nilai seni yang tinggi. Dengan adanya struktur alur tersebut, maka penonton dapat menikmati drama yang dipentaskan.

Berikut ini adalah struktur dalam drama:

1. Babak atau Episode, yaitu bagian dari naskah drama yang merangkum peristiwa yang terjadi di suatu tempat dengan urutan waktu tertentu.

2. Adegan, yaitu bagian dari drama yang menunjukkan terjadinya perubahan peristiwa yang ditandai dengan terjadinya pergantian setting waktu, tempat, dan tokoh.

3. Dialog, yaitu percakapan yang dilakukan oleh dua atau beberapa tokoh dalam drama. Dialog merupakan hal utama yang membedakan drama dengan karya sastra lainnya.

4. Prolog, yaitu kata pengantar ketika akan masuk dalam sebuah drama yang memberikan gambaran umum tentang drama yang dipentaskan. 
5. Epilog, yaitu bagian akhir dari sebuah drama dimana isinya menjelaskan kesimpulan, makna, dan pesan dari drama yang dipentaskan.

\section{d. Unsur-Unsur Drama}

Sama halnya dengan jenis karya sastra lainnya, drama mengandung unsur-unsur penting di dalamnya yang saling berhubungan. Adapun unsur-unsur drama adalah sebagai berikut:

1. Tema, yaitu gagasan utama atau ide pokok yang terdapat dalam cerita drama.

2. Alur, yaitu jalan cerita dari sebuah drama, mulai dari babak awal hingga babak akhir.

3. Tokoh, yaitu karakter dalam drama yang terdiri dari tokoh utama dan tokoh pembantu.

4. Watak, yaitu tingkah laku para tokoh yang ada dalam drama; watak baik (protagonis) dan watak jahat (antagonis).

5. Latar, yaitu gambaran mengenai tempat, waktu, dan situasi yang terjadi dalam drama.

6. Amanat, yaitu pesan yang ingin disampaikan pengarang drama kepada penonton melalui cerita drama.

e. Jenis-Jenis Drama

Drama dapat dibedakan menurut beberapa kategori umum, yaitu berdasarkan penyajian lakon, berdasarkan sarana, dan berdasarkan keberadaan naskah. Adapun beberapa jenis drama adalah sebagai berikut:

A. Berdasarkan Penyajian Lakon

1. Tragedi, yaitu drama yang mengisahkan kesedihan dari tokoh utama dalam drama. Biasanya drama berakhir dengan kisah yang menyedihkan.

2. Opera, yaitu drama yang dialognya dilakukan dengan cara bernyayi dan diiringi musik.

3. Komedi, yaitu drama yang mempertunjukkan kelucuan para tokoh atau alur cerita lucu.

4. Tragekomedi, yaitu drama yang memadukan antara tragedi dan komedi pada waktu yang sama.

5. Melodrama, yaitu drama yang dialog dan lakonnya dilakukan sambil diiringi oleh musik atau melodi.

6. Tablo, yaitu drama yang dilakukan dimana para tokoh tidak melakukan dialog, tapi mengutamakan kemampuan melakukan gerakan tanpa suara seperti pantonim.

7. Farce, yaitu drama yang mempertunjukkan berbagai hal lucu melalui tingkah para pelakon. Mirip seperti dagelan tetapi tidak sepenuhnya sama seperti dagelan.

\section{B. Berdasarkan Sarana}

1. Drama Panggung, yaitu drama yang ditampilkan sepenuhnya di atas panggung dimana para pemain tidak dapat melakukan pengulangan adegan.

2. Drama Televisi, yaitu drama yang ditampilkan di Televisi dimana para pemain dapat melakukan pengulangan adegan karena tidak ditampilkan secara langsung.

3. Drama Radio, yaitu drama yang hanya dapat didengarkan tanpa dilihat. 
4. Drama Film, yaitu drama yang ditampilkan di layar lebar seperti bioskop. Drama ini dapat juga dilihat di Televis, namun setelah diputar di bioskop terlebih dahulu.

5. Drama Wayang, yaitu drama yang diperankan oleh wayang pada setiap adegannya.

6. Drama Boneka, yaitu drama yang menggunakan boneka sebagai tokoh di setiap adegannya.

\section{Berdasarkan Keberadaan Naskah}

1. Drama Tradisional, yaitu drama yang dipertunjukkan dimana para pemeran tidak menggunakan naskah saat berada di panggung. Dalam hal ini, pemeran membaca gambara cerita secara umum dan kemudian berimprovisasi sesuai dengan peran masing-masing.

2. Drama Modern, yaitu drama yang dipertunjukkan dimana para pemeran menggunakan naskah saat berada di panggung. Namun, para pemeran dapat berimprovisasi pada kejadian-kejadian tertentu.

\section{DAFTAR PUSTAKA}

Amanto, B. S., Umanailo, M. C. B., Wulandari, R. S., Taufik, T., \& Susiati, S. (2019). Local Consumption Diversification. Int. J. Sci. Technol. Res, 8(8), 1865-1869.

Amri, M., Tahir, S. Z. A. B., \& Ahmad, S. (2017). The Implementation of Islamic Teaching in Multiculturalism Society: A Case Study at Pesantren Schools in Indonesia. Asian Social Science, 13(6), 125.

Andini, K. NILAI BUDAYA SUKU BAJO SAMPELA DALAM FILM THE MIRROR NEVER LIES KARYA KAMILA ANDINI.

ARYANA, A. PERBANDINGAN GAYA BAHASA DALAM NOVEL ATHEIS KARYA ACHDIAT KARTA MIHARDJA DAN NOVEL TELEGRAM KARYA PUTU WIJAYA: TINJAUAN STILISTIKA.

Azwan, A. (2018). Politeness strategies of refusals to requests by Ambonese community. LINGUA: Jurnal Bahasa, Sastra, Dan Pengajarannya, 15(1), 1-6.

Bin-Tahir, S. Z., Atmowardoyo, H., Dollah, S., Rinantanti, Y., \& Suriaman, A. (2018). MULTILINGUAL AND MONO-MULTILINGUAL STUDENTS'PERFORMANCE IN ENGLISH SPEAKING. Journal of Advanced English Studies, 1(2), 32-38.

Bin Tahir, S. Z. (2017). Multilingual teaching and learning at Pesantren Schools in Indonesia. Asian EFL Journal, 89, 74-94.

Bin Tahir, S. Z. (2015). The attitude of Santri and Ustadz toward multilingual education at Pesantren. International Journal of Language and Linguistics, 3(4), 210-216.

Bin-Tahir, S. Z., \& Rinantanti, Y. (2016). Multilingual lecturers' competence in english teaching at the university of Iqra Buru, Indonesia. Asian EFL Journal, 5, 79-92. 
Bin-Tahir, S. Z., Saidah, U., Mufidah, N., \& Bugis, R. (2018). The impact of translanguaging approach on teaching Arabic reading in a multilingual classroom. ljaz Arabi Journal of Arabic Learning, 1(1).

Bin-Tahir, S. Z., Bugis, R., \& Tasiana, R. (2017). Intercultural Communication of a Multicultural Family in Buru Regency. Lingual: Journal of Language and Culture, 9(2), 8.

Djamudi, N. L., Nurlaela, M., Nazar, A., Nuryadin, C., Musywirah, I., \& Sari, H. (2019, October). Alternative social environment policy through educational values in Kafi'a's customary speech to the kaledupa community of Wakatobi Island, Indonesia. In IOP Conference Series: Earth and Environmental Science (Vol. 343, No. 1, p. 012118). IOP Publishing.

Indonesia, K. K. D. B. Morfologi Bahasa Indonesia.

Iye, R., \& Susiati, S. (2018). NILAI EDUKATIF DALAM NOVEL SEBAIT CINTA DI BAWAH LANGIT KAIRO KARYA MAHMUD JAUHARI ALI (Educative Values in Sebait Cinta di Bawah Langit Kairo by Mahmud Jauhari Ali). Sirok Bastra, 6(2), 185-191.

Iye, R. (2018). Tuturan emosi mahasiswa kota baubau dalam ranah demonstrasi.

Iye, R., Susiati, S., \& Karim, K. (2020). Citra Perempuan dalam Iklan Sabun Shinzui. Sang Pencerah: Jurnal IImiah Universitas Muhammadiyah Buton, 6(1), 1-7.

Iye, R. Jl Prof Dr HAR Basalamah No, and Namlea-Kab Buru.". TUTURAN DALAM PROSESI LAMARAN PERNIKAHAN DI TOMIA KABUPATEN WAKATOBI." Kontemporer. Bandung: PT Remaja.

Karim, K., Maknun, T., \& Abbas, A. (2019). Praanggapan Dalam Pamflet Sosialisasi Pelestarian Lingkungan Di Kabupaten Wakatobi. Jurnal IImu Budaya, 7(2), 241-247.

Lafamane, F. (2020). Tata Bahasa Sistemik Fungsional (Suatu Pandangan).

Lafamane, F. (2020). Perkembangan Teori Sastra (suatu Pengantar). OSF Preprints. July, 25.

Lafamane, F. (2020). Tata Bahasa Fungsional (functional Grammar).

Lafamane, F. (2020). Fenomena Penggunaan Bahasa Daerah di Kalangan Remaja.

Mansyur, F. A., \& Suherman, L. A. (2020). The Function of Proverbs as Educational Media: Anthropological Linguistics on Wolio Proverbs. ELS Journal on Interdisciplinary Studies in Humanities, 3(2), 271-286.

Rahayaan, I., Azwan, A., \& Bugis, R. (2016). The Students' Writing Ability through Cooperative Script Method. Jurnal Retemena, 2(2).

Sadat, A., Nazar, A., Suherman, L. O. A., Alzarliani, W. O. D., \& Birawida, A. B. (2019, October). Environmental care behavior through e-jas model with science edutainment approach. In IOP Conference Series: Earth and Environmental Science (Vol. 343, No. 1, p. 012126). IOP Publishing. 
Sadat, A., Sa'ban, L. M. A., Suherman, L. O. A., Bahari, S., Ibrahim, T., \& Zainal, M. (2019, October). Internalization characters of environmental care and disaster response through care partner schools. In IOP Conference Series: Earth and Environmental Science (Vol. 343, No. 1, p. 012125). IOP Publishing.

Salamun, T. (2018). DEIKSIS PERSONA BAHASA INDONESIA DIALEK AMBON [Personal Deixes of Indonesian Leanguage With Ambonese Dialect]. Totobuang, 5, 325-339.

Salamun, T. (2018). RELASI KEKERABATAN BAHASA HITU, WAKAL, MORELA, MAMALA, DAN HILA DI PROVINSI MALUKU [The Family Relationship Language Hitu, Wakal, Morela, Mamala, and Hila in Maluku Province].

Suherman, L. A. (2018). The Analysis of Metaphorical Domain on English "Stab Verb" in Corpora. ELS Journal on Interdisciplinary Studies in Humanities, 1(1), 52-58.

Suherman, L. O. A., Salam, S., Mursanto, D., Efendi, A., Bahar, S. B., \& Kanna, T. (2019, October). The effect of open-air curing on compressive strength of geopolymer mortar containing laterite soil and slaked lime. In IOP Conference Series: Earth and Environmental Science (Vol. 343, No. 1, p. 012133). IOP Publishing.

Susiati, S., \& lye, R. (2018). Kajian Geografi Bahasa dan Dialek di Sulawesi Tenggara: Analisis Dialektometri. Gramatika: Jurnal IImiah Kebahasaan dan Kesastraan, 6(2), 137-151.

Susiati, S. Dialektometri Segitiga: Hubungan Kekerabatan Bahasa Di Sulawesi Tenggara (Bahasa Wakatobi, Bahasa Cia-Cia, Bahasa Pancana, Bahasa Kioko, Bahasa Tolaki).

Susiati, S., Iye, R., \& Suherman, L. O. A. (2019). Hot Potatoes Multimedia Applications in Evaluation of Indonesian Learning In SMP Students in Buru District. ELS Journal on Interdisciplinary Studies in Humanities, 2(4), 556-570.

Susiati, S. (2018). Homonim bahasa kepulauan tukang besi dialek kaledupa di kabupaten wakatobi [the homonymon of tukang besi island languange in kaledupa dialect at wakatobi regency]. Totobuang, 6 (1), 109, 123.

Susiati, S. (2020). Emosi Verbal Suku Bajo Sampela.

Susiati, S. (2020). Fenomena Tuturan Emosi Verbal Bahasa Indonesia Suku Bajo Sampela.

Susiati, S. (2020). Nilai Budaya Suku Bajo Sampela Dalam Film The Mirror Never Lies Karya Kamila Andini.

Susiati, S. (2020). Konsep Pertentangan Dalam Film" Aisyah Biarkan Kami Bersaudara" Karya Herwin Novianto.

Susiati, S. (2020). Strategi AMBT untuk Meningkatkan Kemampuan Membaca Pemahaman Interpretatif Siswa Kelas IV SD Negeri 3 Namlea Kabupaten Buru.

Susiati, S. (2020). Fungsi Konatif Pada Iklan Mesin Cuci Hole-Less Tub Dari Sharp: Analisis Wacana Kritis. 
Susiati, S. (2020). GAYA BAHASA SECARA UMUM DAN GAYA BAHASA PEMBUNGKUS PIKIRAN.

Susiati, S. (2020). The Concept Of Togetherness In The Films" Aisyah Biarkan Kami Bersaudara" By Herwin Novianto.

Susiati, S. (2020). Konsep Kebersamaan Dalam Film" Aisyah Biarkan Kami Bersaudara" Karya Herwin Novianto.

Susiati, S. (2020). Teori dan Aliran Linguistik: Tata Bahasa Generatif.

Susiati, S. (2020). Metode Pembelajaran Bahasa Indonesia: Sosiodrama.

Susiati, S. (2020). Rekontruksi Internal Bahasa Bugis dan Bahasa Makassar: Linguistik Komparatif.

Susiati, S. Bahan Ajar: Psikolinguistik.

Susiati, S. (2020). PENTINGNYA MELESTARIKAN BAHASA DAERAH.

Susiati, S. (2020). Morfologi Kelas Kata Dalam Bahasa Indonesia.

Susiati, S. (2020). Semantik: Teori Semantik, Relasi Makna, Marked, Dan Unmarked.

Susiati, Y. T. Risman Iye. A. Kesantunan Imperatif Bahasa Indonesia Suku Bajo Sampela: Balai Pembinaan dan Pengembangan Bahasa. 2018. Kongres Bahasa Indonesia (No. 12, pp. 1-6). Report.

Susiati, S. (2020). Internal Recontruction Bugis Language and Makassar Language.

Susiati, S. (2020). Kesantunan Imperatif Bahasa Melayu Ambon.

Susiati, S. (2020). Gaya Bahasa Secara Umum Dan Gaya Bahasa Pembungkus Pikiran: Stilistika.

Susiati, S. (2020). Tuturan Kesantunan Imperatif Bahasa Indonesia Suku Bajo Sampela.

Susiati, S. (2020). Nilai Budaya Suku Bajo Sampela Dalam Film The Mirror Never Lies Karya Kamila Andini.

Susiati, S. (2020). Pengaplikasian Multimedia Hot Potatoes Dalam Evaluasi Pembelajaran Bahasa Indonesia Pada Siswa SMP Negeri 9 Buru.

Susiati, S., \& lye, R. (2018). Kajian Geografi Bahasa dan Dialek di Sulawesi Tenggara: Analisis Dialektometri. Gramatika: Jurnal IImiah Kebahasaan dan Kesastraan. 6 (2), 137-151.

Susiati, S. (2020). Kaidah Fonologi Bahasa Indonesia.

Susiati, S. (2020). Wujud Morfologi Bahasa Indonesia.

Susiati, S. (2020). Makian Bahasa Wakatobi Dialek Kaledupa.

Susiati, S. (2020). Eksistensi Manusia Dalam Film" Aisyah Biarkan Kami Bersaudara" Karya Herwin Novianto. 
Susiati, S. NILAI BUDAYA SUKU BAJO SAMPELA DALAM FILM THE MIRROR NEVER LIES.

Susiati, S. (2020). Konsep Keterasingan Dalam Film" Aisyah Biarkan Kami Bersaudara" Karya Herwin Novianto.

Susiati, S. (2020). Concept Of Conflict In The Films "AISYAH BIARKAN KAMI BERSAUDARA" By Herwin Novianto.

Susiati, S. (2020). Embrio Nasionalisme Dalam Bahasa dan Sastra.

Susiati, S. PERWUJUDAN SIMILE OLEH MERARI SIREGAR DALAM NOVEL AZAB DAN SENGSARA.

Susiati, S. (2020). Nilai Pembentuk Karakter Masyarakat Wakatobi Melalui Kabhanti Wa Leja.

Tahir, S. Z. A. B. (2017). Pengembangan Materi Multibahasa untuk Siswa Pesantren. Unpublish dissertation.

Tahir, S. Z. B. (2015). Multilingual Teaching And Learning At Pesantren. 14 Asian EFL Journal Conference.

Tenriawali, A. Y. (2018). Representasi korban kekerasan dalam teks berita daring tribun timur: analisis wacana kritis [the representation victims of violence in tribun timur online news text: critical discourse analysis]. TOTOBUANG, 6 (1), 1, 15.

Yusdianti, A. (2020). THE REPRESENTATION VICTIMS OF VIOLENCE IN TRIBUN TIMUR ONLINE NEWS TEXT: CRITICAL DISCOURSE ANALYSIS. 